\title{
Determinismo e livre arbítrio nas ciências sociais: contributos matemáticos -
}

\author{
Determinism and free will in social sciences: \\ mathematical contributions
}

FRANCISCO LOUÇÃ*

RESUMO: O artigo examina algumas das críticas poderosas desenvolvidas contra o paradigma do equilíbrio geral, em particular aquelas que foram apresentadas do ponto de vista de novas ideias da matemática e da física. Maxwell, Duhem, Poincaré, Hurst e Mandelbrot, como muitos outros, contrastaram o universo da simplicidade - a base do teorema do limite central e a maior parte da inferência estatística tradicional - com o universo da complexidade organizada, argumentando que a auto-poiese e a coordenação são realmente características gerais de nossos sistemas físicos ou sociais. O impacto dessas discussões em economia é apresentado, pois algumas críticas à teoria do equilíbrio geral e, em particular, ao programa da Comissão Cowles emergiram dessa intuição sobre a complexidade: Sims, Granger, Wold, Hendry e outros economistas, estatísticos ou matemáticos expressaram suas reservas em relação à tradição e cultura ortodoxas em nossa ciência. As estratégias heterodoxas atuais são discutidas na última parte do artigo.

PALAVRAS-CHAVE: Metodologia da economia; história do pensamento econômico.

ABSTRACT: The paper surveys some of the powerful criticisms developed against the paradigm of general equilibrium, in particular those that were presented from the viewpoint of new insights from mathematics and physics. Maxwell, Duhem, Poincaré, Hurst and Mandelbrot, as many others, contrasted the universe of simplicity - the basis for the central limit theorem and most of traditional statistical inference - with the universe of organized complexity, arguing that auto-poiesis and coordination are indeed general features of our physical or social systems. The impact of these discussions in economics is then presented, since some criticisms to the theory of general equilibrium and in particular to the Cowles Commission programme emerged from this intuition on complexity: Sims, Granger, Wold, Hendry and other economists, statisticians or mathematicians expressed their reservations in relation to the orthodox tradition and culture in our science. The current heterodox strategies are discussed in the last part of the paper.

KEYWORDS: Economic methodology; history of economic thought.

JEL Classification: B41; B00.

\footnotetext{
* Instituto Superior de Economia e Gestão, Universidade Técnica de Lisboa, Lisboa, Portugal. E-mail: flouc@iseg.ulisboa.pt. Orcid https://orcid.org/0000-0001-9661-6157.
} 
No dia 11 de fevereiro de 1876, James Clerk Maxwell, provavelmente o físico britânico mais famoso do seu tempo, apresentou uma conferência a que deu o título algo provocador de "Does the Progress of Physical Science Tend to Give an Advantage to the Opinion of Necessity (or Determinism) over that of Contingency of Events and the Freedom of Will?”. O texto, que foi publicado escassos anos depois, é um testemunho notável de uma polémica filosófica perene acerca da essência humana e da liberdade. Mas tem a particularidade, que é o que interessa para o presente texto, de a discutir a partir do ponto de vista do cientismo do final do século XIX, isto é, de um dos momentos culminantes da emergência e afirmação do positivismo como padrão epistemológico para as ciências. Assim, esta conferência é um documento fundamental para compreender as bifurcações filosóficas do noso tempo, no que diz respeito ao próprio conceito de ciência, e de ciência social em particular.

Maxwell começou por indicar a distinção entre dois tipos de conhecimentos, obtidos a partir do método estatístico, inspirado em Laplace e definidos pela determinação das características de dados universos, e os derivados do método analítico dinâmico, "o único perfeito, em princípio" (Maxwell, 1876: 438). O que distinguiria ambos os métodos não seria a sua aplicação em campos do conhecimento distintos, as ciências sociais e as naturais: pelo contrário, ambos se definem ou se aplicam a um objeto comum, as sociedades organizadas. Assim, Maxwell diz-nos que o primeiro método estaria particularmente adequado ao tipo de estudo desenvolvido pela sociologia e seria inspirado pela estatística laplaceana, enquanto o segundo seria mais completo e histórico por natureza, dado que pretenderia “ observar homens individuais [e não grupos amostrais indistintos], definir a sua história, analisar os seus motivos, e comparar as expectativas sobre o seu comportamento com a sua conduta real" (ibid.).

Ora, este método dinâmico pretenderia obter um estatuto epistémico superior ao do método estatístico: ao primeiro caberia descrever, mas só o segundo permitiria compreender e explicar os fundamentos das ações. Nesse momento da sua exposição, Maxwell introduziu então pela primeira vez o referencial da mecânica, a ciência do movimento, dedicada ao estudo das uniformidades: no contexto dos processos mecânicos, a previsão é possível, e o "problema da profecia” pode ser resolvido como na astronomia, mas nos "problemas históricos" existiria uma assimetria essencial entre o passado e o futuro que o tornaria impossível. A distinção deveria ser estabelecida então entre uma classe de fenômenos estáveis (dinamicamente estáveis) e uma outra de fenômenos instáveis, que foram definidos com rigor:

"Quando o estado das coisas é de tal modo que uma variação infinitamente pequena do estado presente só alterará numa infinitamente pequena quantidade o estado num momento futuro, a condição de um sistema, esteja em repouso ou em movimento, é dita estável; mas quando uma variação infinitamente pequena no estado presente pode implicar uma variação finita no estado do sistema num momento finito, a condição do sistema é dita instável. É manifesto que a existência de condições instáveis 
torna impossível a predição de acontecimentos futuros, se o nosso conhecimento dos estados presentes for somente aproximativa, e não exata." (ibid.: 440)

No contexto de sistemas estáveis, conclui-se então a primazia do determinismo: "O nosso livre arbítrio será no melhor dos casos semelhante ao dos átomos de Lucrécio $^{1}$ - que em momentos e lugares incertos se desviam de um modo incerto do seu curso" (ibid.: 441). O livre arbítrio estaria, portanto, reduzido a uma classe de variações incognoscíveis.

No entanto, Maxwell deu-se conta de que a história não ficava por aqui, e que a velha dicotomia entre mecanicismo e sistemas indeterminados, ou entre relações causais e necessárias e livre arbítrio, podia ser perturbada por uma outra classe de fenômenos que seria impossível classificar segundo os métodos anteriormente expostos e segundo a taxionomia geralmente aceita. Paradoxalmente, estes fenômenos seriam provavelmente os mais comuns, e os exemplos abundam na conferência: a refracção de um raio num cristal, a avalanche ${ }^{2}$ provocada por uma simples pedra, uma fagulha que incendeia a floresta, uma palavra que impede uma ação. Assim,

"Existem outras classes de fenômenos que são mais complicados, e em que pode ocorrer instabilidade, aumentando o número destes casos, de um modo inexcedivelmente rápido, com o aumento do número de variáveis. (... ) É de esperar que em fenômenos de complexidade mais elevada haverá um número muito maior de singularidades, nas quais o axioma sobre as causas idênticas que produzem efeitos idênticos deixará de ser verdade." (ibid.: 442-3)

Para acentuar ainda mais o seu argumento, Maxwell termina escrevendo que os "pontos singulares" com estas características, tais que tornam a previsão impossível, são frequentes sobretudo em organizações mais complexas - "a nossa própria natureza” - e que assim ressurge a questão do livre arbítrio. Pois se mesmo em sistemas determinados tal patologia pode ocorrer, e se for paradoxalmente normal como expressão da complexidade organizacional das sociedades - que faz intervir um número crescente de variáveis-, então é de presumir que a instabilidade estrutural seja dominante nos sistemas sociais. A escolha torna-se, portanto, possível em sistemas tão complexos e é reivindicada como parte intrínseca da natureza humana (ibid.: 444).

\footnotetext{
1 "A ponto de estabelecer rigorosas leis mecânicas que determinam todo o acontecimento, [Lucrécio] sente a necessidade de conceder aos átomos desvios imprevisíveis em relação à linha reta, de modo a garantir tanto a liberdade da matéria quanto a liberdade dos seres humanos. A poesia do invisível, a poesia das potencialidades imprevisíveis e infinitas, tal como a poesia do nada, nascem de um poeta que não tem qualquer dúvida sobre o carácter físico do mundo" (Italo Calvino, Lezione Americane).

${ }^{2}$ Aparentemente, os autores que recentemente têm desenvolvido a teoria da criticalidade auto-organizada (como Per Bak), ignoram este predecessor ilustre e inspirador.
} 
Esta conferência é notável a vários títulos. Em primeiro lugar, é raro encontrar um físico destacado que dedicasse os seus ócios a uma reflexão tão imbuída de implicações filosóficas e sociais, e em particular nestes anos dos finais do século XIX em que o cientismo positivista parecia inquestionável. Em segundo lugar, a discussão é transferida do domínio dos sistemas mecânicos para o campo dos sistemas sociais. Em terceiro lugar, sugere que todos estes tipos de sistemas podem ser modelizados por objetos matemáticos mais complexos, em que o livre arbítrio é recuperado, já não como mera aleatoridade à imagem e semelhança dos átomos de Lucrécio, mas como forma intrínseca de organização complexa das relações entre agentes dotados de discernimento. Pouco depois, Poincaré seguiu a mesma intuição e chegou a conclusões semelhantes, tendo-se esforçado por definir esta classe de objetos matemáticos com maior rigor.

O texto presente avalia a importância destas intuições em relação com um dos enigmas cruciais da economia: a determinação de modelos para os ciclos econômicos, definindo a causalidade e o campo da política econômica e previsões possíveis quanto às flutuações conjunturais e mudanças estruturais.

\section{ESTRATÉGIAS ORTODOXAS E OS SEUS PROBLEMAS}

A economia como ciência foi desde logo atraída pelo problema da variação no tempo: por que é que num período se tem prosperidade e noutro miséria? Por que varia a produção, o emprego, a exportação? Por que é que há inflação e deflação? As respostas a estas e outras questões semelhantes foram sendo baseadas na intuição e no raciocínio, até que novos instrumentos estatísticos e de modelização matemática sugeriram que poderia haver uma solução tecnicamente exata para medir, determinar e prever essas flutuações. A história do cavalo-de-balouço ${ }^{3}$ já foi contada noutra ocasião (Louçã, 1997), e sugere que foi a estrita separação entre um aparelho determinista e uma abordagem estatística baseada na inferência a partir dos erros aleatórios que permitiu o progresso do confirmacionismo econométrico e a solução (provisória) para a questão.

A homogeneidade e regularidade empírica assumidas pela econometria tradicional, com a hipótese conexa de constância dos parâmetros, ou com a hipótese de um amplo universo de que seria obtida a amostra em estudo, a definição da probabilidade como o limite das frequências relativas e a estratégia de Neyman-Pearson para o teste de hipóteses, foram assumidas como condições teóricas para o

\footnotetext{
${ }^{3} \mathrm{O}$ uso da metáfora do cavalo-de-balouço para descrever os ciclos econômicos surge de uma observação de Ackerman em relação a Wicksell, e que foi retomada e divulgada por Ragnar Frisch, que lhe deu forma matemática. Concebe-se um mecanismo dissipatório (o cavalo, cuja friç̧ão o faz tender para o equilíbrio), um agente impulsionador (a criança em cima do cavalo, cujo movimento perpetua a ação, até a abandonar). O sistema dinâmico que representa este processo foi apresentado por Frisch em 1933, e veio a ser a razão principal para a obtenção do seu Prêmio Nobel em 1969 - e que foi o primeiro concedido a um economista.
} 
desenvolvimento do programa de investigação. Ora, desde muito cedo alguns economistas criticaram esta estratégia, como foi o caso, suficientemente conhecido, de Keynes. É menos conhecida a atitude de outros, entre os quais a de um dos primeiros críticos de Keynes: Leontief, apesar de ser um dos primeiros críticos da "Teoria Geral”, alinhou-se com a oposição de Keynes ao conceito da não-homogeneidade das séries no tempo. Nesse sentido, descreveu em 1953 o trabalho de adivinhação econométrica com uma metáfora muito eloquente: a tarefa do econometrista é como se ele ou ela tivesse que desenhar os planos técnicos de um motor de um automóvel com base no conhecimento comum do seu funcionamento, e sem outra informação que não fosse o ruído do motor e as indicações do painel de comandos. Para mais, acrescenta Leontief, na economia temos mudanças permanentes na estrutura do motor, induzidas pela sua própria evolução (Leontief, 1966: 60-1). Assim, como Maxwell, Leontief foi levado a duvidar da relevância de um universo de objetos matemáticos simplistas.

Ora, a prática econométrica contradiz diretamente a preocupação de Leontief e a sua denúncia da metáfora mecânica; se se quer que a adivinha seja descoberta, tem de se supor que o motor nunca muda. Protestando contra as conclusões excessivas sobre a realidade, inferidas de pequenos modelos de três ou cinco variáveis, Leontief sugeriu em alternativa o desenvolvimento de análise direta dos fatos.

A crise profunda deste programa foi registrada por alguns dos autores que têm vindo a rejeitar o programa da Comissão Cowles: por Sims (que criticou a tentativa de identificar as equações simultâneas), por Granger (que criticou a simultaneidade), por Friedman, por Wold (se bem que este tenha mais tarde aceitado a estimação estrutural; Epstein, 1987: 6). Mas outros foram mais longe, questionando mesmo algumas das hipóteses básicas, apesar de manterem a exigência de um grande rigor formal para o desenvolvimento de novos instrumentos estatísticos para analisar as séries reais.

Hendry, por exemplo, assumiu processos de desequilíbrio de longo prazo, que deveriam ser aproximados por estruturas de lags e por ajustamentos dinâmicos. Outra abordagem importante dos métodos estatísticos é a bayesiana: as probabilidades são subjetivas ${ }^{4}$, os parâmetros são variáveis aleatórias, e as observações são úteis para corrigir as opiniões apriorísticas e a distribuição de probabilidade dos parâmetros. Neste contexto, e esse é o tema que para aqui interessa, assume-se plenamente a diferença das ciências sociais em relação às ciências experimentais: $\mathrm{o}$ erro na especificação pode manter-se qualquer que seja a dimensão da amostra dado que não existe regularidade e homogeneidade nos dados. Esta óbvia diferen-

\footnotetext{
${ }^{4}$ Isto é de novo uma crítica à metáfora física: “ Os economistas herdaram das ciências físicas o mito de que a inferência científica é objetiva, e isenta de preconceitos pessoais. Isto é um total disparate. Todo o conhecimento é crença humana; mais precisamente, opinião humana. $\mathrm{O}$ que frequentemente acontece é que nas ciências físicas é que existe uma alto grau de conformidade de opinião (... ). O falso ídolo da objetividade provocou muitos danos à ciência econômica" (Leamer, 1983: 36). Esta opinião relativista expressa por Leamer não é uma pré-condição para aceitar o seu argumento acerca da característica subjetiva da probabilidade ou da especificação do modelo.
} 
ça em relação à economia mecanicista não exclui a possibilidade de uma análise rigorosa: a análise de sensibilidade e um acréscimo de evidência empírica pode ajudar a investigar a natureza dos preconceitos do cientista, e nesse sentido a probabilidade condicional incorpora abertamente uma noção de incerteza. Este tratamento da subjetividade é um avanço muito importante na estatística e na contestação de alguns dos limites da sua prática corrente ${ }^{5}$.

Finalmente, alguns autores, como Georgescu-Roegen, atacaram o "organon walrasiano", o "dogma mecanicista" e o "aritmomorfismo" 6 , a partir do ponto de vista geral da metáfora biológica e da reconceptualização evolucionista da economia. Esta estratégia alternativa baseada no conceito de evolução orgânica nos processos históricos irreversíveis tem algumas consequências para as questões aqui tratadas: (i) estabelece severos limites ontológicos para a hipótese tradicional da existência de regularidades empíricas nos fenômenos estudados pela econometria: a realidade é complexa, a escolha e a mudança são generalizadas na evolução econômica e portanto não se admite que uma lei geral e determinística represente a vida social; (ii) assim sendo, rejeita a prova indutiva de leis gerais, sugerindo a adoção de formas mais débeis de implicação; (iii) estabelece múltiplas formas de determinação causal. Nesse caso, a análise deve rever o que a econometria tradicional considera serem casos patológicos, dado que são a condição natural da maior parte das séries: no processo sequencial, a auto correlação não deve ser considerada uma inconveniência ou uma perturbação, mas antes uma característica corrente indicando a dependência cronológica (path-dependency) na evolução social, tal como a heteroscedasticidade é sintomática de que ocorrem fatos fora do equilíbrio.

Esta mudança de paradigma que é assim sugerida tem paralelos com o que ocorre noutras ciências. Quando a astronomia era considerada a rainha das ciências, o primeiro conceito de erro aleatório baseava-se numa origem singular de variabilidade dos dados, os erros não-sistemáticos de medida. Estendida por Laplace ao domínio das ciências sociais, o recurso à probabilidade foi então definido como a consequência inevitável da ignorância do investigador. Em qualquer dos casos, as observações nas séries econômicas eram consideradas como sendo geradas por processos essencialmente determinísticos, epistemologicamente autônomos de outras fontes de variação que poderiam ser descritas por uma única variável aleatória agregada representando o "erro". Nesse sentido, as frequências e modos de flutu-

\footnotetext{
5 “Dividimo-nos confortavelmenteentre um sacerdócio celibatário de teóricos estatísticos, por um lado, e uma legião de analistas que são pecadores inveterados, por outro lado. Os padres são empossados do poder de fazerem as listas dos pecados e são reverenciados pelo seu especial talento nesse sentido. Não se espera que os pecadores evitem os pecados; só precisam de confessar abertamente os seus erros" (Leamer, 1978: VI).

6 "Na verdade, qualquer sistema que envolva um princípio de conservação (dados meios) e uma regra de maximização (satisfação ótima) é uma analogia mecânica" (Georgescu-Roegen, 1971: 318). Georgescu-Roegen criticou a epistemologia da Comissão Cowles, nomeadamente a hipótese da constância dos parâmetros, o processo de amostragem 'como se' e as conclusões determinísticas, e sugeriu uma abordagem dialética.
} 
ação são considerados independentes e aditivos, permitindo a distinção entre crescimento e ciclo e a análise separada de cada tipo de ciclo e a diferenciação nítida entre formas extrínsecas de causalidade e formas intrínsecas de inteligibilidade.

Mas esta explicação foi questionada, como se viu com a história de Maxwell, a partir da própria física pela introdução da irreversibilidade com a segunda lei da termodinâmica, e pelas definições preliminares de complexidade: por Maxwell, mas também por Duhem ou Poincaré, pelos finais do século XIX. Um exemplo brilhante é a discussão sugerida pelo último acerca do problema dos três corpos, que foi então definido como um enigma perturbador e que não podia ser satisfatoriamente resolvido pela mecânica newtoniana; como Poincaré suspeitava, sabe-se agora que, se as trajetórias dos três corpos são interdependentes, não podem ser completamente previstas (Ruelle, 1991: 108). Na terminologia contemporânea, isto significa que se pelo menos três osciladores são relacionados, pode ocorrer caos, e isto mesmo foi provado recentemente por Xia: três corpos gravitacionalmente interdependentes no espaço vazio exibem propriedades caóticas, mesmo que a massa de um deles seja reduzida a uma ínfima dimensão (Xia, 1994: 289 s.). O sistema solar, como outros, é caótico; por maioria de razão, é de presumir que o sejam as sociedades e as economias.

$\mathrm{Na}$ economia como numa análise da sociedade organizada, há naturalmente razões para crer que a interação de muitos agentes e instituições diferentes pode criar processos complexos. Mas os ciclos, para voltar ao tema original, foram interpretados como os efeitos da ação à distância num universo atomístico newtoniano, portanto como o resultado de modos de oscilação determinísticos, independentes e, portanto, sobreponíveis: o nosso velho amigo, o cavalo-de-balouço, é o exemplo paradigmático, e o máximo que poderia acontecer seria uma imprevisibilidade atômica à Lucrécio. Mas se os modos de oscilação estiverem relacionados e forem dependentes do tempo, os ciclos múltiplos exibirão dependência sensível às condições iniciais e criarão irregularidades: aí temos a turbulência nas economias, e "Não deixa de ser razoável afirmar que vivemos hoje numa tal economia" (Ruelle, 1991: 110-1).

Se assim for, a inferência estatística tradicional, tal como é atualmente usada nas séries cronológicas, está errada ou é suspeita e novos métodos devem ser usados para resolver os enigmas colocados pela evolução econômica - não tanto porque os modelos de equilíbrio, as especificações lineares e a inferência probabilística estejam tecnicamente incorretos mas sim porque são aplicados corretamente aos fenômenos e às questões erradas.

Resta perguntar por que é que esta estratégia foi tão bem-sucedida, se bem que se baseasse em fundamentos epistemológicos tão limitados e duvidosos. Uma resposta possível é que se baseava no consenso da época, na ciência normal comumente aceite. E esse consenso foi gerado pelos sucessos do cientismo positivista durante gerações sucessivas. $\mathrm{O}$ reducionismo foi o terreno comum do cartesianismo, para o qual uma explicação era equivalente à partição do problema nas suas ínfimas componentes, e do indutivismo de Newton e de Hume, que estabeleceu a confirmação empírica do atomismo. Essa estratégia epistemológica inspirou a aná- 
lise dos ciclos econômicos e tomou a forma da dupla decomposição: a discriminação entre o trend, o lugar do equilíbrio, e o ciclo, os seus desvios, e depois a discriminação no próprio ciclo entre o sistema de propagação, uma vez mais a estrutura de equilibrio, e o sistema de impulso. O paradigma do equilíbrio justificou a decomposição e legislou acerca do valor explicativo do modelo: a parte sistemática representava as propriedades desejáveis de convergência, embora tivessem ainda que se assumir outras hipóteses acerca da natureza do erro, para que a inferência estatística viesse a ser possível.

Essas hipóteses não são intuitivas, dado que implicam a agregação de um conjunto heteróclito de erros de especificação, de variáveis conhecidas e desconhecidas, de entidades quantificáveis e não quantificáveis. É por isso que o Teorema do Limite Central é tão decisivo: declara um resultado muito poderoso e muito geral e, com as condições apropriadas, permite a agregação de variáveis distintas sob a forma de um único termo aleatório cuja condição de distribuição é conhecida.

As condições decisivas são, portanto, a independência e a variância finita das componentes do termo agregado - e a aplicabilidade dessas condições foi o motivo da discussão nas ciências sociais. Quetelet, o discípulo de Laplace que formalizou a lei malthusiana da população e cuja leitura influenciou a aceitação por Darwin do conceito de seleção natural, declarava que cada indivíduo é imprevisível, mas que agregadamente a população segue a lei dos erros nos desvios do comportamento médio (Morgan, 1990: 7). Assim, quando Chebyshev formulou a lei (1887) e Pearson a interpretou como a base para a inferência estatística, o conceito estava firmemente estabelecido e tinha sido sucessivamente confirmado por um grande número de experiências de todos os tipos.

Em consequência, Galton argumentou que a "lei da frequência do erro" era universal nas estruturas sociais:

"Quanto maior a multidão, e maior a aparente anarquia, mais perfeita é a sua influência [da lei normal]. É a lei suprema da falta de razão. Quando quer que uma ampla amostra de elementos caóticas seja obtida e ordenada pela sua grandeza, prova-se que esteve sempre latente uma insuspeita e bela forma de regularidade.” (Galton, citado em Peters, 1994: 197)

Por outras palavras, o Teorema do Limite Central descreve a imposição da ordem a partir da desordem: se com Newton e Descartes estávamos ainda no mundo da ordem e dos fenômenos simples a serem explicados por leis universais, a simplicidade criando simplicidade, o Teorema leva-nos a outro mundo, em que é a complexidade que gera simplicidade. Este resultado tão poderoso é a base para a inferência estatística ${ }^{7}$.

\footnotetext{
${ }^{7}$ A este respeito, na primeira edição da revista científica Complexity, o editorialista John Casti (1995: 12-3) argumenta que há três leis gerais na emergência da complexidade: a descrita pelo Teorema, a representação de Fourier das funções como uma soma de infinitas séries de senos e cosenos, e a Lei da Potência, por exemplo a Lei de Zipf sobre a frequência das palavras, ou
} 
Uma nova solução foi, no entanto, proposta no princípio do século XX, num local distante, por um cientista que eventualmente ignorava a inquietação de Maxwell e cujos trabalhos só recentemente foram descobertos e reinterpretados. Em 1906, Hurst, um físico com um doutoramento em Oxford, foi recrutado para trabalhar no Egito para o governo. Passou no país quarenta e seis anos da sua vida e, desde 1913, trabalhou nos projetos de barragens do Nilo, a maior parte do tempo dirigindo o departamento responsável pelo controlo do rio. Depois de trinta e oito anos de trabalho, conhecia suficientemente o Nilo e publicou os resultados das suas investigações, que são surpreendentes.

O problema original de Hurst era calcular a capacidade máxima necessária para os reservatórios das barragens. Dispunha para isso de um registo excepcional dos níveis do rio, dado que o Nilo tinha sido sempre tão importante para a civilização agrícola da região e se dispunha de uma anotação cuidadosa dos seus níveis por vários séculos, e muito rigorosa desde 622 (Hurst, 1952: 259-60). A partir da inspeção desses registos, Hurst queria calcular a dimensão da reserva necessária nos bons anos para alimentar as necessidades dos anos de seca, para construir as barragens.

Naturalmente, adaptou a hipótese de que as inundações seguissem um passeio aleatório, tal como os jogos de pura sorte como a roleta. Mas reparou de imediato que havia uma patologia nas séries: podiam ser detectados longos períodos de grandes inundações e longos períodos de secas. Por outras palavras, se as séries como um todo podiam ser corretamente descritas pela curva normal, tal como esperado pela hipótese aleatória, permanecia ainda assim uma estrutura:

"Era claro que o armazenamento necessário para o caso de descargas do rio, chuvas etc. era maior do que a que corresponderia a puros acontecimentos ocasionais. Isto é devido à tendência, já mencionada, dos acontecimentos naturais se agruparem em períodos em que predominam os valores altos ou baixos." (Hurst, 1952: 298)

Hurst conferiu um grande número - setenta e cinco - de outros fenômenos naturais, da espessura dos anéis das árvores da Califórnia até às marcas da lama nos leitos dos rios, dos preços do trigo às manchas solares, valores da temperatura e pressão, e encontrou as mesmas características (ibid.: 297):

"Em todos os casos até agora estes métodos assumiram que as descargas anuais são aleatórias, isto é, que a descarga anual não tem relação com as suas predecessoras. $\mathrm{O}$ exame de algumas centenas de casos de fenômenos naturais(...) mostra que se bem que um ano não esteja relacionado com os seus predecessores, os anos de alta e de baixa tendem a aparecer em grupos." (Hurst, Black, Simaika, 1966: 125)

a relação entre a queda e a dimensão dos meteoritos, os terramotos, a especiação, a dimensão das cidades etc. 
Se a ordem dos acontecimentos fosse ignorada, o Teorema poderia ser aplicado e os seus resultados seriam convincentes. Mas se a ordem fosse considerada, então emerge "qualquer coisa de mais complicado" (ibid.: 59; 106). Esta suspeita foi então verificada com a ajuda distante de Robert Brown, que tinha descoberto em 1828 que havia uma relação entre o tempo da observação e a distância percorrida por uma partícula seguindo uma trajetória errática: Einstein determinou os valores aproximados e, muito simplesmente, a equação é $d=t^{0.5} \cdot \mathrm{O}$ movimento browniano foi usado para representar processos multidimensionais e independentes comparáveis aos jogos de azar. Inspirado neste cálculo, Hurst determinou o que chamou de rescaled range (R/S): normalizou as séries como desvios da média, de modo a calcular a amplitude máxima da nova série formada pelos valores normalizados e acumulados. Esta amplitude indica a distância atravessada pelo sistema no caso das observações utilizadas, e Hurst descobriu que, depois da normalização, esta poderia ser descrita pela equação $R / S=c n^{k}$, onde $c$ é uma constante e $n$ o número de observações: o valor de $\mathrm{R} / \mathrm{S}$ cresce com o tempo.

Se o expoente $\mathrm{K}$, segundo Hurst, ou mais tarde chamado $\mathrm{H}$ em homenagem ao autor, é 0.5 , temos então o movimento browniano, e este resultado foi verificado por experiências exaustivas com jogos de cartas. De outro modo, se $0 \leq \mathrm{H}<0.5$, temos ruído cor de rosa, o fenômeno anti-persistente da turbulência, como por exemplo a volatilidade nos mercados de capitais; se $0.5<\mathrm{H} \leq 1$, temos então ruído negro, o fenômeno persistente do reforço do trend. O sistema tem, de fato, memória do seu passado e não existe independência das observações sucessivas. No caso do Nilo e de outros fenômenos naturais em causa, Hurst encontrou valores entre 0.72 e 0.81: é o "efeito de José", sete anos de abundância, sete anos de escassez, uma forte dependência em relação ao passado. A análise RIS e o expoente de Hurst podem, portanto, ser usados para discutir séries estatísticas suficientemente longas e para detectar o efeito da memória e de estruturas profundas que podem estar escondidas pela lei do Teorema ou pela aleatoridade aparente do sistema.

Peters usou o método para verificar a premissa tradicional da eficiência e da distribuição normal dos rendimentos do mercado: a teoria standard afirma que qualquer ação é independente das anteriores, que nenhum investidor aprende com o passado, e que o mercado é eficiente desde que existam investidores com horizontes temporais diferentes (Peters, 1991: 14; 1994: 42) - a ordem é criada a partir da desordem. Peters verificou que as séries financeiras não seguem realmente a curva normal, como esperado: algumas são processos de ruído cor de rosa, outras de ruído negro, algumas exibem curtose, abas largas, que são aberrações no universo gaussiano.

Veja-se por exemplo uma série histórica dos movimentos de uma grande Bolsa. Apresentará, naturalmente, as características irregulares dos voláteis mercados financeiros, com diversos trends longos em períodos distintos. O gráfico será irregular: anos de prosperidade seguem-se a anos de depressão, as contrações e recuperações cíclicas são sucessivamente indicadas, a economia cresce e muda. Se o método de decomposição fosse adequado, poderíamos separar o trend de crescimento e o ciclo, e identificar o mecanismo de equilíbrio do ciclo - os parâmetros 
constantes das variáveis explicativas - e o efeito agregado dos choques aleatórios, o termo residual ou o erro da equação. Mas, dado que não conhecemos o sistema exato, seríamos forçados a proceder às arrecuas e a usar métodos indiciários, ou seja, a assumir que podemos recorrer à inferência estatística dado que o termo aleatório deve ser normalmente distribuído; nesse caso, os resultados são acertados. De fato, a prova está facilmente disponível: se extrairmos o trend da série com uma curva exponencial e ajustarmos um processo auto-regressivo adequado, obtemos facilmente uma série de resíduos aleatórios sem evidência de auto-correlação linear.

Mas, como Hurst provou, a aparência de gaussianidade pode esconder estruturas importantes. Se for utilizada em alternativa a análise R/S, como por exemplo numa série S\&P500 da Bolsa de Nova York, obtemos H=0.78: aqui está a evidência de um processo browniano fraccional (Louçã, 1997: 314). A série é gerada por um processo de ruído negro, em que o trend se reforça: apesar de tudo, a conclusão é óbvia, dado que a economia presumivelmente tem memória longa. No caso do Nilo, Hurst calculou $\mathrm{H}=0.72$ : se se tratasse de um processo de ruído branco $(\mathrm{H}=0.5)$, a probabilidade de uma inundação num ano se seguir a outro ano de inundação seria de $50 \%$; de fato, esse acontecimento é mais provável do que o contrário e foi isso que Hurst descobriu depois de décadas de observação e de investigação acerca das séries de que dispunha. Tinha uma explicação para isso: a complexidade cria complexidade. Na série da Bolsa norte-americana, salta à vista uma explicação semelhante: as depressões e expansões não são acontecimentos aleatórios, mas sim serialmente correlacionados e parte de uma estrutura. De novo, aí está na complexidade.

Pode-se argumentar que não é dada uma prova concludente para essa afirmação, sobretudo se uma técnica estatística tradicional e bem identificada conduz a resultados opostos. Por agora, considere-se unicamente a explicação destes fenômenos: acontecimentos interdependentes e relações complexas são de esperar, apesar de tudo. Toda a ideia da evolução de um sistema movido por choques aleatórios e independentes atuando sobre um maravilhoso mecanismo que cria a estabilidade e a convergência parece estar muito distante da realidade. Bastaria que fossem utilizadas razões teóricas e descritivas, para que a balança da evidência se inclinasse para a abordagem da complexidade. Mas, mesmo assim, é indispensável uma prova estatística.

Ora, os resultados obtidos a partir das séries de preços especulativos não são a primeira exceção à regra do Teorema. Muitos anos antes, Pareto tinha detectado que a distribuição de riqueza seguia a curva normal, exceto os 3\% da população mais rica, para os quais seguia uma lei de potência: uma "aba larga". Recentemente, Dosi e alguns colegas encontraram uma distribuição estável de Pareto na dimensão das empresas (Dosi et al.,1994: 26-27). Muitos outros observadores confirmam este resultado geral: abas largas, uma e outra vez.

Estas patologias foram estudadas já há muito tempo na estatística. Mesmo sem recorrer aos métodos indispensáveis da dinâmica não linear, tanto Maxwell como Poincaré identificaram o problema essencial: pequenas causas provocam grandes efeitos (Poincaré, 1908: 87) - é o "efeito Noé”, identificado por Hurst e mais tarde por Mandelbrot. Nesse caso, a complexidade não conduz à simplicidade: as obser- 
vações sucessivas não são como amostras retiradas de jogos de roleta, mas representações concretas de processos sequenciais na vida social. Presumivelmente, não são geradas por processos independentes e os pequenos choques aleatórios não se compensam. Existe uma estrutura: há o tempo, mas há também o clima; há crises e expansões, mas há também uma economia.

Essas eram as conjecturas de Benoit Mandelbrot, um cientista da IBM, quando estudou no início dos anos sessenta os preços do algodão e algumas séries de preços especulativos no mercado de Chicago, onde encontrou fenômenos que não correspondiam à lei normal: anos de alta especulação seguiam-se com maior probabilidade a outros anos especulativos e a metáfora da roleta não se aplicava. Para analisar estes fenômenos, Mandelbrot descobriu e usou o método R/S de Hurst: confirmou os desvios da normalidade. Deve acrescentar -se que estava preparado para enfrentar esta conclusão: um dos professores de Mandelbrot, Paul Lévy, tinha defendido muito antes que a distribuição normal era somente uma de uma família de "distribuições estáveis", de que apenas se conhecem as funções de densidade para a de Gauss, de Cauchy e de Lévy. A normalidade e a regra do Teorema só podem ser impostas com a condição da variância finita; se assim não acontece e se existe dependência de longo prazo, então os procedimentos tradicionais, a OLS, a análise espectral, os modelos ARIMA, a estimação por máxima verossimilhança, tudo isso se torna suspeito. O fato de serem usados apesar disso é a prova conclusiva da submissão à metáfora física omnipotente:

"A única razão para assumir a continuidade [em vez de processos descontínuos e eventualmente não-gaussianos] é que muitas ciências tendem, sabendo-o ou não, a copiar os procedimentos que se revelaram tão bem-sucedidos na física newtoniana. Mas os preços são diferentes: a mecânica não inclui nada semelhante.” (Mandelbrot, 1983: 335)

Hurst, Mandelbrot e muitos outros detectaram este efeito Noé: no fluxo do Nilo, em engarrafamentos do trânsito (Bak, 1996: 21 s.), em séries de preços especulativos, na evolução econômica e social - o movimento browniano fraccional está por toda a parte em sistemas complexos dissipativos. Nas séries reais bem como numa nova geração de modelos: seguindo Bak e Chen, Scheinkman e Woodford estudaram algumas simulações de criticalidade auto-organizada, em que podem ser produzidas avalanches por pequenas modificações em sistemas instáveis, e descobriram que o limite da dimensão das avalanches era uma lei de potência (Scheinkman, Woodford, 1994: 419). Estas avalanches são de fato os casos limite das estruturas criadas em séries longas: anos de inundações sucedem-se a anos de inundações. Tinha sido exatamente essa a conclusão de Mitchell: quando ajustava a curva normal para as percentagens de crescimento em 5.578 séries de preços, Mitchell tinha achado um certo número de casos de abas largas (Mirowski, 1989: 80). Abas largas, de novo. Mais tarde, quando estudou os preços de matérias primas e de ações, Mandelbrot aplicou pela primeira vez na economia o conceito de dimensão fractal. Esse foi um dos seus argumentos a favor de um segundo estádio 
do indeterminismo: escrevia Mandelbrot que o indeterminismo do primeiro estádio, comparando o estudo das trajetórias econômicas com o comportamento estocástico aprendido na evolução das partículas de um gás, era irrelevante para a maioria dos fenômenos sociais dado depender de flutuações ligeiras e da gaussianidade (Mandelbrot, 1987: 118). De fato, a economia deslocou-se do mundo euclidiano ou cartesiano da ordem e da geometria perfeitas para a abordagem probabilista e para o programa econométrico: esse era o indeterminismo do primeiro estádio, importante dado que razões extrínsecas impediam o conhecimento positivo completo. Em alternativa, Mandelbrot defendeu um indeterminismo da segunda geração, considerando as interações não-lineares e a emergência de fenômenos complexos, o que hoje se chama de atratores estranhos, ou seja, indeterminismo intrínseco.

Quando os artigos de Mandelbrot foram publicados, foram a primeira investigação empírica importante a usar o método de Hurst e a criticar o fundamento da aplicação geral do Teorema aos fenômenos sociais. As implicações deste trabalho estão patentes no Premature Fractal Manifesto (1964, mas só publicado em Mandelbrot, 1987), em que o autor discute as implicações epistemológicas do uso das metáforas físicas - e foi ignorado. A economia não estava preparada para abandonar os seus dogmas, mas ainda assim outra razão mais poderosa interveio para criar um nevoeiro de silêncio à volta do trabalho de Mandelbrot: nesse momento, o programa da Comissão Cowles abandonara os seus primeiros trabalhos econométricos sobre a estimação de um sistema de equações e adotara uma forma extrema de bourbakismo, que evitava a análise empírica.

Depois de detectadas as dificuldades da estimação estrutural no final dos anos quarenta, Koopmans, Malinvaud, e acima de tudo Debreu com a sua Theory of Value de 1959, regressaram ao cartesianismo: na sua nova interpretação do papel da matemática na economia, as estruturas predominariam sobre os problemas e os teoremas sobre a análise empírica. Tal como Mandelbrot afirma, isto era o protótipo de uma "estrutura completamente auto-referencial", de uma "abordagem de cima para baixo" alheia a qualquer preocupação de interpretar a realidade (Mandelbrot, 1989: 10-11).

O programa bourbakista foi inicialmente desenvolvido por um grupo semi secreto de matemáticos franceses, que adoptaram em 1935-1935, como pseudônimo, o nome de um obscuro general do século anterior, Nicholas Bourbaki, para com ele assinarem os seus coletivos manuais de cálculo, em que procuravam reconstruir a ciência de um ponto de vista rigoroso. O trabalho do grupo era regido por um contrato muito bizarro: quem quer que atingisse cinquenta anos devia abandoná-lo. Mas era muito disciplinado e bem-sucedido, e tornou-se a força impulsionadora da axiomatização de diversas ciências.

Um dos seus discípulos, justamente Gérard Debreu, exportou o programa para os EUA e tornou-se a figura central da transformação da econometria e da economia matemática. As consequências foram imensas: "O objetivo já não era interpretar a economia, o que quer que isso significasse, mas antes codificar a própria essência dessa entidade enigmática, o sistema walrasiano" (Weintraub, Mirowski, 1994: 265) - sob as ordens do general Bourbaki e a inspiração positivista 
lógica da estratégia de Cowles, a axiomatização tornou-se uma nova linguagem para a economia.

A emancipação da economia das restrições da realidade era de fato a condição necessária para o desenvolvimento do paradigma do equilíbrio geral, através da axiomatização extensiva. Para grande desgosto da epistemologia popperiana, isto implicava igualmente a rejeição das estratégias refutacionistas, bem como o abandono dos esforços anteriores de identificação, interpretação e explicação dos fenômenos da vida real. E, como nos garante o princípio do Panda, as crises subsequentes do paradigma e a inabilidade dos seus mentores em provarem as condições simultâneas de existência, unicidade e estabilidade do equilíbrio postulado, foram sendo resolvidas com barragens de axiomatização e com sofisticados desenvolvimentos bourbakistas.

Não é, portanto, surpreendente que Mandelbrot, segundo as suas próprias palavras, tenha deixado a França devido à dominação da axiomática na academia ou que tenha regressado à inspiração da obra de Poincaré, o "diabo incarnado" para Bourbaki (Mandelbrot, 1989: 11), no sentido de compreender as características excepcionais da dinâmica não linear e da instabilidade estrutural. E é ainda menos surpreendente que tenha sido ignorado ao fazê-lo.

$\mathrm{Na}$ mesma vertente de Mitchell, Mandelbrot recapitulou estas críticas, como Keynes tinha feito antes dele. Os seus argumentos acerca da complexidade intrínseca, irredutível à simplicidade, são resultados impressionantes pelos padrões atuais, mesmo que formulados de outro modo. Mas ficaram enterrados até a recente crise do paradigma neoclássico. É tempo de regressarmos ao futuro.

\section{ESTRATÉGIAS HETERODOXAS}

Em consequência, é necessário definir novos caminhos para as investigações futuras, em particular nos dois campos que parecem mais prometedores e mais exigentes: a modelização da segunda geração do indeterminismo, o estudo concreto das dinâmicas complexas, e a modelização histórica, o estudo complexo das realidades concretas. Uma síntese evolucionista não está ainda no horizonte, mas a acumulação dos sinais da crise do positivismo, particularmente na última dúzia de anos, e o desenvolvimento de novos métodos estatísticos ou de novas investigações históricas tendem a reforçar este projeto.

As raízes mais profundas do problema foram identificadas há muitos anos, nomeadamente por Maxwell como se viu, que notou que existem outras classes de fenômenos que são mais complicadas, e em que ocorrem casos de instabilidade, aumentando o número dessas ocorrências em relação com o número de graus de liberdade do sistema (Maxwell, 1876: 442). E Poincaré tinha certamente razão quando escrevia que:

"A observação revela-nos cada dia novos fenômenos; devem esperar muito tempo e, por vezes, para lhes dar lugar é preciso destruir uma parte de 
um edifício. Mesmo nos fenômenos conhecidos, em que os nossos crus sentidos nos tinham mostrado uniformidade, percebemos detalhes cada dia mais variados; o que acreditávamos ser simples torna-se complexo, e a ciência parece avançar para a variedade e a complexidade." (Poincaré , 1903: 148)

Foi isto precisamente que Hurst e Mandelbrot descobriram: há volatilidade dos preços, mas há também uma estrutura da evolução. E dado que sistemas evolucionistas em larga escala se tendem a organizar, a selecionar as suas propriedades seletivas, é fundamental um estudo da interação da morfogénese e da estrutura, para se compreender um vasto corpo de fatores que influenciam as economias. A recuperação do estatuto da economia como ciência social depende da viabilidade desta nova economia histórica e social.

Resta sugerir que uma estratégia alternativa deve explorar três eixos de reconstrução - tanto nas suas implicações na determinação dos sistemas matemáticos adequados quanto na interpretação dos fatos: a morfogénese; a auto-organização; a coordenação.

1. A morfogénese implica duas propriedades essenciais: mudança e controle, i.e., ruptura e continuidade. Coexistem e são mesmo interdependentes e inseparáveis: a unilateralidade da análise de um único dos termos desse processo é responsável por grande parte do irrealismo nas teorias econômicas, sendo exemplos das teorias da continuidade as definidas pelo paradigma do equilíbrio geral.

Turing, celebrado como um precursor das ciências da computação mas frequentemente ignorado como um dos descobridores da complexidade, modelizou a morfogénese através de um sistema químico muito simples de dois componentes com taxas de difusão diferentes, sob choques aleatórios: o sistema atingia o "limiar da instabilidade" dadas as suas propriedades auto-catalíticas - a emergência de um padrão de organização ou a concentração de um componente dominante prova que no modelo é a instabilidade que implica o desenvolvimento da estrutura (Turing, 1952: 37). Ordem a partir da complexidade: como nos modelos de Waddington, tal como assinalado por Turing, uma ordem biológica emerge não só da seleção natural, mas também das propriedades dinâmicas do sistema.

Há evidentemente diferenças substanciais e sutis entre esses sistemas orgânicos e químicos simples e os sociais. O equilíbrio entre retro-acões positivas e negativas nos nichos ecológicos, a canalização do desenvolvimento, a seleção dos espaços de viabilidade e de estabilidade são essencialmente dirigidos por processos coordenados naturalmente, enquanto nas economias e nas sociedades há uma combinação de processos naturais e de escolha consciente e de ação intencional. Nesse sentido, a coordenação social pode ser definida pela ação de dois conjuntos relacionados de variáveis: (i) os sub-sistemas tecnológico, econômico, político, institucional e cultural, e (ii) as variáveis que relacionam esses sub-sistemas.

2. As sociedades e as economias reais têm, como outras estruturas dissipativas, a propriedade de auto-organização. Essa constatação tem duas consequências maiores. Em primeiro lugar, desde a explosão do mito da reversibilidade do tempo, su- 
blinha a importância da história e requer outra forma de investigação que não a baseada em modelos artificiais definidos com o propósito de exibirem as qualidades estéticas do equilíbrio. Em segundo lugar, exige uma economia política, no sentido clássico do termo, pois a auto-organização é a forma que toma em cada momento a coordenação, que é a relação de poder.

Desde os primeiros dias das leis universais de Newton e da simplicidade organizada, foi percorrido um longo caminho. Com Boltzmann, a simplicidade desorganizada foi formalizada: com o Teorema do Limite Central, os estatísticos basearam as suas técnicas na assunção da complexidade que criava a simplicidade. $\mathrm{O}$ que tem sido sugerido agora é uma mudança decisiva de paradigma: a complexidade é irredutível à simplicidade; a complexidade e a ordem fora do equilíbrio explicam a evolução.

Foram discutidos múltiplos processos de coordenação ao longo deste texto. $\mathrm{Na}$ biologia evolucionista, os exemplos mais salientes são a seleção social de processos anti-seletivos, o efeito reversivo darwinista de Tort, ou a eliminação pela seleção natural das espécies mais instáveis, de modo a aumentar a estabilidade ecológica. Kauffman, rejeitando que a seleção natural seja o único processo de criação da ordem biológica, ou que o organismo seja um conjunto não-intencional e ad hoc de células, concebe formas de seleção de grupo e de dinâmicas complexas no limiar do caos, que explicariam a criação e as formas da vida; como se viu, antes dele Waddington tinha sugerido um duplo processo de seleção, organísmico e populacional. Esta opinião segue a de Waddington, que sugeriu um processo de seleção dupla ao nível organísmico e populacional:

"A Seleção Natural mantém os sistemas genéticos complexos no espaço dinâmico entre a liberdade e a fixidez, o único em que a evolução pode ter lugar, e explica assim uma propriedade profunda das coisas vivas que bem pode ser chamada de 'evolvabilidade'.” (Depew, Weber, 1996: 21)

Estes conceitos são darwinistas e apesar disso desafiam o Dogma Central neodarwinista e weissmanniano: a evolução darwinista micro está acoplada com as propriedades dinâmicas dos sistemas auto-organizados (Bak, 1996: 129), e evolui no limiar do caos (Kauffman, 1995: 15).

$\mathrm{Na}$ economia, os processos de coordenação foram igualmente discutidos desde os autores clássicos e, sobretudo, desde a revolução marginalista e a definição do paradigma do equilíbrio (a "mão invisível" de Smith, o processo de tâtonnement e a metáfora do lago de Walras): o equilíbrio geral foi na economia a primeira formalização bem definida de um processo de coordenação. Grande parte dos consideráveis recursos intelectuais postos ao serviço deste paradigma do equilíbrio geral foi dedicada a estabelecer as condições da existência e da estabilidade do equilíbrio; como se sabe, isso correspondeu igualmente a uma abstração crescente, ao predomínio de uma epistemologia relativista e à axiomatização progressiva da disciplina. E falhou rotundamente.

O conceito de simplicidade organizada, a mão invisível, estava condenado a 
deformar a realidade onde quer que ocorressem fenômenos complexos e emergentes. Foram então desenvolvidos novos esforços para reparar os erros dos axiomas do equilíbrio, da certeza e da racionalidade, nomeadamente através da teoria dos jogos e em particular do conceito do equilíbrio de Nash. No entanto, se há vários agentes com estratégias alternativas, o modelo não garante a convergência para um simples atrator de equilíbrio, e se há alguma perturbação a nova trajetória do sistema não é previsível a priori. Os resultados foram desproporcionais ao esforço e alguns dos líderes do projeto tomaram desde então as suas distâncias ou criticaram mesmo abertamente o fracasso global do programa.

A coordenação deve ser entendida como um processo mais vasto do que o equilíbrio geral: Schumpeter definiu a dinâmica do capitalismo através de uma função social especial e desequilibrante, a do empresário inovador. E, naturalmente, o crescimento histórico do peso e do âmbito da ação governamental pode ser interpretado como uma expressão da necessidade de coordenação em sociedades e economias cada vez mais complexas e imprevisíveis. A coordenação é irrelevante sem co-evolução.

3. A coordenação é o conceito usado para interpretar os sistemas de controlo e as funções coesivas no desenvolvimento histórico. A coordenação, como um processo social sujeito a interações complexas - e não o equilíbrio, que é um estado -, explica os atratores em padrões de crescimento, o peso das instituições sociais, a relação entre o sistema econômico e outras partes da sociedade. Estabelece, deste ponto de vista, a condição de viabilidade teórica da metaforização da morfogénese, originalmente definida ao nível organísmico, e que é transcrita no plano geral do processo evolucionista de uma sociedade. Por outras palavras, a coordenação explica por que é que os processos de desequilíbrio existem mas estão sujeitos a restrições, porque é que diferentes ritmos estão inter-relacionados (mode-locked) e porque é que a instabilidade estrutural persiste mas não conduz o sistema à explosão. Durante décadas, a coordenação foi identificada com o equilíbrio geral. Isto é compreensível, dado que o paradigma neoclássico assumiu desde o início que tais processos dominavam as economias e, mais, que eram representáveis pelos axiomas da existência, da unicidade e da convergência para o equilíbrio. A coordenação, através do leiloeiro, do sistema de preços e do seu modo de circulação da informação, foi definida como extremamente simples, automática e eficiente ${ }^{8} \mathrm{e}$

\footnotetext{
${ }^{8}$ É certo que o problema da coordenação é discutido pela economia neoclássica e é mesmo uma das características centrais das suas teorias, dado queéincorporado nas premissas fundamentais do paradigma. Mas é uma premissa escondida, dado que a coordenação éconsiderada simultaneamente como o resultado da concorrência - como na Fábula das Abelhas de Mandeville ou a Lei de Say - e como a própria natureza da concorrência - dado que o agente representativo, cujo comportamento maximizador é o paradigma da racionalidade, atua espontaneamente de modo a coordenar o mercado. Alguns autores neoclássicos, evidentemente, tinham perfeita consciência de que tal descrição simplista da realidade não podia ser mantida caso se mudassem as premissas: como Marshall indicou, se fosse adaptada uma perspectiva histórica - uma visão de longo prazo - em vez de uma visão de curto prazo, então as retroações positivas e negativas implicariam não-linearidades (por exemplo, rendimentos crescentes) e a coordenação deixaria de corresponder ao equilíbrio e à estabilidade
} 
tornou-se a base para uma visão geral do mundo e da ação humana. De fato, o modelo de impulso-propagação foi tão poderoso e bem-sucedido porque incorporou e estendeu estes conceitos, domesticou e adaptou as variáveis estocásticas que emergiam da revolução quântica e tornou possível a corroboração empírica e a predição: a análise dos ciclos econômicos não podia aspirar a mais. Assim, modelizou a coordenação como um mecanismo de equilíbrio, com Frisch a amortecer os choques de Slutsky, como um bem comportado e sempre previsível cavalo de balouço. Mas rapidamente a coordenação se transformou num jogo de lógica para a economia ortodoxa, e o abandono do programa econométrico para a estimação estrutural e a subsequente adesão ao bourbakismo conduziu a economia aos píncaros da axiomatização e dos prazeres do instrumentalismo.

Ora, um dos cumes do instrumentalismo é o modo de modelização tipicamente utilizado no desenvolvimento das teorias econômicas. Em particular, a própria epistemologia da distinção entre variáveis exógenas e endógenas, essencial para a determinação lógica do modelo, implica severas restrições à hipótese de escolha racional humana - e, portanto, ao livre arbítrio que preocupava Maxwell e tantos outros. Pois se só as variáveis exógenas são objetos da escolha, dado que as endógenas são deterministicamente impostas pelo sistema, existe uma contradição entre essa margem de liberdade no espaço do modelo e a pretensão do conhecimento, pois a endogeneização é legitimamente a forma de explicar o sistema (Lawson, 1997). Um curioso reconhecimento deste paradoxo foi produzido no contexto das expectativas racionais por nem mais nem menos do que Sargent e Wallace:

"O paradoxo com que os economistas se defrontam pode ser resumido deste modo. Para que um modelo tenha implicações normativas, deve conter alguns parâmetros cujos valores possam ser escolhidos pelo decisor político. Mas se esses puderem ser escolhidos, os agentes racionais não os identificarão como fixos e utilizarão esquemas para prever os seus valores. Se os economistas modelizam as economias tomando em consideração estes esquemas, então esses parâmetros tornam-se endógenos e já não aparecerão nas formas reduzidas das equações das outras variáveis endógenas. Se modelizarem a economia sem tomar em consideração estes esquemas, não estarão a impor a racionalidade.” (Sargent, Wallace, 1976: 183)

Esta contradição opõe, portanto, a tentativa de endogeneizar as variáveis como forma privilegiada de inteligibilidade - no sentido em que o modelo abarca toda a realidade, à Laplace - e o reconhecimento das margens de manobra para compreender o que escapa ao determinismo radical ou o que é campo de atuação específica de agentes dotados de poder funcional. A dicotomia é dramática: ou se compreende, e compreender é a condição para agir, mas compreendendo deixa de ser possível agir, ou se age, embora sem compreender, simplesmente porque uma e outra forma social depende de classes de variáveis mutuamente exclusivas no contexto desta modelização simplista e instrumentalista.

Uma das exceções a esta epistemologia, e uma das mais interessantes e contra- 
ditórias figuras da economia do século XX que participou neste debate acerca da coordenação, foi Hayek. Hayek evoluiu de uma posição tradicional de equilíbrio geral, nomeadamente nos seus modelos de ciclos, para a ideia de uma "ordem espontânea": estas duas versões do problema da coordenação são claramente opostas, ao ponto de vários investigadores terem descrito estas fases como "Hayek I" e "Hayek II". Para o primeiro, o mecanismo de mercado era necessário e suficiente para a coordenação, dado que estabelece a informação perfeita dos preços numa sociedade atomista perfeita: em consequência, supunha que os mercados são eficientes, e que os ciclos econômicos são devidos a erros de sobre-investimento monetário, perturbações exógenas a serem dissipadas pelo sistema de preços. Mas, desiludido com o equilíbrio geral, Hayek abandonou a análise dos ciclos pelo final dos anos trinta. Como assinalado na discussão anterior acerca da incorporação da metáfora física, Hayek era muito crítico do enviesamento "cientista" da economia, que levava à transposição ilegítima dos conceitos de optimização de energia e de equilíbrio obtidos em experiências laboratoriais para as teorias econômicas, e defendeu alternativamente metáforas orgânicas para explicar os fenômenos sociais. Assim, a sua eficiência de mercado não era obtida pelas tradicionais propriedades mecânicas, mas pela hipótese extrema da racionalidade e do individualismo metodológico. Hayek II, pelo seu lado, sublinhou as regras de conduta mutuamente impostas como uma forma viável de coordenação, e obtinha-se assim uma aproximação ao equilíbrio pelas forças de mercado, se bem que este nunca fosse realmente atingido: essas "forças ordenadoras espontâneas" (Hayek, 1974: 34) eram parte do organismo social, como a "interação espontânea das ações dos indivíduos,(...) [num] organismo em que cada parte cumpre a função necessária para a continuação do todo, sem que nenhum ser humano o tenha determinado" (Hayek, 1933: 130-1). Neste contexto, o equilíbrio de curto prazo seria uma ficção abstraindo-se do tempo (Hayek, 1928: 161-2), não teria "significado definido" e "estas tentativas de dar ao conceito do equilíbrio uma interpretação realista (cuja legitimidade permanece em qualquer caso em dúvida) retiraram-nos pelo menos um uso importante, que o conceito teria se reconhecêssemos francamente o seu carácter puramente fictício" (Hayek, 1941: 21). No longo prazo, o equilíbrio poderia eventualmente ser definido como um centro de gravitação, mas por razões práticas, isto implica a existência de um processo concreto de coordenação sem equilíbrio dado que o estado da informação está em mudança permanente (Garretsen, 1992: 83-4).

Nos seus últimos escritos, Hayek abandonou virtualmente a economia e dedicou-se ao desenvolvimento das suas opiniões filosóficas, defendendo a utilidade social da metáfora da seleção natural: a sociedade evoluiria através da concorrência de diversos grupos, lutando para impor as suas próprias regras - a ordem espontânea era a propriedade emergente desta estrutura em que a complexidade dominava a evolução societal num processo predominantemente lamarckiano e não darwinista. De fato, esta metáfora orgânica era próxima da sociobiologia, sendo a transmissão cultural na sociedade modelizada como um processo de seleção e auto-organização (Witt, 1993: xxii). Em resumo, em Hayek I a coordenação era imposta pela eficiência do sistema de preços do mercado, como na história neoclássica, e em 
Hayek II a coordenação era imposta pela seleção: em ambos os casos, o mercado e as forças naturais deveriam conduzir o sistema para o estado desejado. Kirzner sintetizou esta abordagem argumentando que a ação empresarial leva ao equilíbrio: isto é justamente o contrário da teoria Schumpeteriana (Kirzner, 1973: 72) - mas é incoerente, dado que fora do equilíbrio são criadas tanto a ordem como a desordem.

Tal como Hayek, Keynes considerou as metáforas orgânicas, mas chegou a conclusões diferentes: a coordenação foi por ele modelizada como uma função específica de um conjunto de instituições ou convenções, nomeadamente da moeda e das autoridades e mecanismos monetários, que seriam fundamentais dado o fracasso eventual dos mecanismos de mercado. De fato, o "paradoxo da poupança" pode e deve ser interpretado como o resultado de um erro de coordenação: dado que a poupança e o investimento são decisões tomadas por agentes diferentes em momentos diferentes com motivações diferentes, podem implicar desequilíbrio, como aconteceu frequentemente.

No entanto, tanto a abordagem neoclássica do problema da coordenação quanto os modelos específicos propostos por Keynes supõem a contenção, o carácter fechado do sistema, e consequentemente rejeitam implicitamente ou não podem incorporar a dimensão histórica de sistemas abertamente co-evolucionistas. As explicações da coordenação desenvolvidas no contexto das teorias dos ciclos deveriam ter abordado o tema, mas a maior parte delas restringiu a resposta ao estudo do funcionamento de um sub-sistema, fosse o econômico, fosse o tecnológico. Como foi anteriormente argumentado, estas posições são insatisfatórias, porque isolam muito artificialmente os sub-sistemas em função de alguma noção de causalidade; e, apesar disso, essa noção não pode ser testada empiricamente. Por outro lado, tendem a ignorar as características institucionais e sociais, dado que não podem ser simplesmente incluídas no modelo formal que representa a teoria ${ }^{9}$.

A importância da inspiração metafórica dos modelos orgânicos e a sua superioridade em relação às alternativas mecanicistas pode ser medida neste contexto: a seleção e a mutação substituem o equilíbrio, a criação da variedade substitui a maximização, a dissipação e a coordenação do desenvolvimento substituem a conservação. A auto-organização, a auto-regulação e o crescimento são parte deste sistema autopoiético: o desequilíbrio e a coordenação são duas partes da mesma realidade - como Hegel escreveu, transformar-se é a verdade do ser.

A coordenação e a complexidade permitem explicar simultaneamente as ondas longas ou os estádios do desenvolvimento econômico - i.e., a auto-organização - e as características de imprevisibilidade dos mesmos processos econômicos. De fato, todas as sociedades têm limites materiais e sociais em cada momento da sua evolução: a complexidade não implica trajetórias dispersas para todos os azimutes.

\footnotetext{
${ }^{9}$ Uma das tentativas de o fazer foi a de Ronald Coase, que desde 1937 identificou os custos de coordenação e de informação: os custos de investigação, de negociação, os custos da conclusão de contratos ou da vigilância sobre contratos. Só com a imposição de restrições implausíveis a esses processos é que se pode manter o postulado do equilíbrio geral.
} 
Pelo contrário, trata-se de processos indeterministas mas sujeitos a restrições, seja pelo passado, seja pelas dotações materiais da economia, seja ainda pelas características das forças que influenciam o poder e coordenam a sociedade. Neste caso, a estabilidade é configurada através de instituições bem definidas em cada período histórico: o paradigma tecno-econômico pode ser representado por um atrator que seleciona uma banda larga de processos cíclicos e atrai essas órbitas, o que é conhecido nas economias sob a forma dos ciclos de vida das indústrias dominantes, das constelações de inovações radicais, da evolução das instituições sociais que incluem as organizações do trabalho, as formas de conflito, ou as culturas que definem uma sociedade.

Deste modo, os modelos complexos não-lineares tratam a dualidade da estabilidade dinâmica (em torno dos atratores, numa região limitada pela disponibilidade dos recursos materiais, do trabalho ou das capacidades tecnológicas) desiste mas que são também estruturalmente instáveis (conduzindo a mudanças de regime a partir de mudanças na estrutura). Algumas características centrais das economias reais são corretamente metaforizadas por estes modelos evolucionistas: o capitalismo é instável e contraditório, mas controla os seus processos de acumulação e reprodução. Mais ainda, a instabilidade crítica gera novos desenvolvimentos e novas fases de estabilidade dinâmica: esta característica morfogenética é a força particular do capitalismo que fascinou Schumpeter e foi tão vivamente descrita por Marx e Engels no Manifesto Comunista como o programa da modernidade. "Tudo o que é sólido se dissolve no ar", a adaptação permanente e a morfogénese são os instrumentos da estabilização estrutural das economias.

O equilíbrio representou a evolução, sublinhando unilateralmente o papel da coordenação e postulando metafisicamente a convergência e a estabilidade, ignorando o papel construtivo do tempo - tratava um problema real, mas era incapaz de o resolver. A deficiência do paradigma do equilíbrio geral torna-se óbvio quando se verifica a sua radical inconsistência com a história e a evolução.

Os processos históricos e sociais, em contrapartida, são instáveis, e essa é a paradoxal e fascinante característica que atraiu tanta atenção e esforço para decifrar o enigma. Por isso, os economistas procuram determinar por que é que as economias são sensíveis às condições iniciais, i.e., são historicamente determinadas, e porque é que não explodem, i.e., como é que são coordenadas, e não o conseguiram ainda. Algumas respostas são agora conhecidas, apesar dos equívocos gerados durante gerações pela noção do equilíbrio: existem atratores, porventura estranhos, no processo co-evolutivo das economias, para o qual os fundadores do paradigma, e Walras em particular, foram alertados em vão por Poincaré ou depois por Volterra: o equilíbrio descreve laboratorialmente atratores fixos em uma ou em duas dimensões, mas estas condições experimentais são irreprodutíveis ou inconcebíveis nas economias. Para mais, se três ou mais osciladores independentes são relacionados, o caos emergirá.

A atenção deve, portanto, concentrar-se em processos mais gerais, e antes de mais nada na coordenação no contexto co-evolucionista que gera complexidade. Em particular, a coordenação é o processo de seleção de conectividade (dos valores, 
da arquitetura e dos estados da rede) de modo a maximizar a estabilidade dinâmica: diversos autores descreveram este tipo de processos como o limiar do caos ou da turbulência, mas nenhuma dessas definições é porventura muito rigorosa, dado que o caos descreve objetos geométricos fixos em espaços de fases fixos, e os organismos vivos ou os organismos sociais são dotados de outras propriedades de mudança e de intencionalidade. Por outro lado, o conceito de caos determinístico não é satisfatório no caso dos sistemas sociais, dado que existem fatos e fatores fora do controlo do sistema - como quer que ele seja definido - que devem ser considerados externos e não determinados. A noção de limiar do caos não é, tampouco, muito clara, pois não são bem definidas as fronteiras entre a aleatoridade pura e a stasis pura (Mirowski, 1996: 15-6).

Mas o novo paradigma é já por si um importante passo em frente, dado que destrói os conceitos ortodoxos tradicionais, reinstala a história, e reconduz a ciência à sua função: explicar e compreender, formular e corrigir hipóteses e conjecturas, aprender. A economia não alcança o estatuto de ciência através das suas proposições sobre o equilíbrio, a racionalidade e o determinismo perfeito: em vez disso, o que se encontra em sistemas abertos e evolucionistas é desequilíbrio e turbulência, não-linearidades, não-convexidades, racionalidade limitada e ação intencional ou institucional.

A complexidade não pode ser reduzida à simplicidade, como Maxwell intuiu corretamente desde 1876. É tempo de o levar a sério e de procurar uma nova via para a aproximação entre as ciências.

\section{REFERÊNCIAS}

BAK, Per (1996), How Nature Works - The Science of Self-Organized Criticality, New York: Springer Verlag.

CALVINO, Italo (1988), Lezioni Americane. Roma: Garzati.

CASTI, John (1995), “The Bell Curves and Monkey Languages - When do Empírica Relations Become a Law of Nature?”, Complexity, 1(1), pp. 12-5.

DEPEW, D. \& WEBER, B. (1996), Darwinism Evolving - System Dynamics and the Genealogy of Natural Selection, Cambridge: MIT Press.

DOSI, G., FREEMAN, C. \& FABIANA, S. (1994), “The Process of Economic Development: Introducing some Stylized Faces and Theories on Technologies, Firms and Institutions”, Industrial and Corporate Change, 9(1), pp. 1-45.

GARRETSEN, Harry (1992), Keynes, Coordination and Beyond-The Development of Macroeconomic and Monetary Theory since 1945, Aldershot: Edward Elgar.

GEORGESCU-ROEGEN, N. (1971), The Entropy Law and the Economic Process, Cambridge, Massachusetts: Harvard University Press.

HAYEK, F. (1928), "The System of Intertemporal Price Equilibrium and Movements in the "Value of Money”', in Kirzner, I. (ed.), Classics in Austrian Economics, 11. III, London: Pickering, pp. 161198.

HAYEK, F. (1933), “The Trend of Economic Thinking”, Economica, 13, pp. 121-37.

HAYEK, F. (1941), The Pure Theory of Capital, London: Routledge.

HAYEK, F. (1974), “The Pretence of Knowledge”, in Hayek, F. (1978), pp. 23-34.

HAYEK, F. (1978), New Studies in Philosophy, Politics, Economics and the History of Ideas, London: Routledge. 
HURST, H. (1952), The Nile - A General Account of the River and the Utilization of its Waters, London: Constable.

HURST, H., BLACK, R. \& SIMAIKA, Y. (1966), The Nile Basin, vol. X of The Major Nile Projects, Cairo: Government Printing Offices.

KAUFFMAN, Stuart (1995), At Home in the Universe-The Search for Laws of Self-Organization and Complexity, Oxford: Oxford University Press.

KIRZNER, I. (1973), Competition and Enterprise, Chicago: Chicago Univ. Press.

LAWSON, Tony (1997), Economics and Reality. London: Routledge.

LEAMER, Edward (1978), Specification Searches: Ad Hoc Inferences with Nonexperimental Data, New York: Wiley.

LEAMER, Edward (1983), “Let's Take the Con out of Econometrics”, American Economic Review, 73, March, pp. 31-43.

LEONTJEF, W. (1966), Ensayos sobre Economia, Barcelona: Planeta Agostini.

LOUÇÃ, Francisco (1997), Turbulência na Economia - Uma Abordagem Evolucionista de Ciclos e da Complexidade em Processos Históricos, Porto: Afrontamento.

MANDELBROT, Benoit (1983), The Fractal Geometry, New York: Freeman.

MANDELBROT, Benoit (1987), “Towards a Second Stage of Indeterminism in Science”, Interdisciplinary Science Reviews, 12, pp. 117-27.

MANDELBROT, Benoit (1989), “Chaos, Bourbaki, and Poincaré”, Mathematical Intelligencer, 11(3), PP. $10-2$.

MAXWELL, J. C. (1876), "Does the Progress of Physical Science Tend to Give any Advantage to the Opinion of Necessity (or Determinism) over that of Contingency of Events and the Freedom of Will?”, in Campbell, L.; Garnett, W., The Life of James Clark Maxwell, With a Selection from his Correspondence and Occasional Writings and a Sketch of His Contributions to Science, London: MacMillan, ed. 1882, pp. 434-44.

MIROWSKI, Philip (1989), “Tis a Pity Econometrics Isn't an Empirical Endeavor: Mandelbrot, Chaos, and the Noah and Joseph Effects", Ricerche Economiche, 18(1-2), pp. 76-99.

MIROWSKI, Philip (1996), "Do You Know the Way to Santa Fé? or, Political Economy Gets More Complex”, in Pressman, Steve (org.), New Directions in Political Economy: Malvern after Ten Years, London: Routledge.

MORGAN, Mary (1990), The History of Econometric Ideas, Cambridge: Cambridge Un iv. Press.

POINCARÉ, Henri (1903), Science and Hypothesis, New York: Walter Scott Pub. Co.

POINCARÉ, Henri (1908), Science et Méthode, Paris: Flammarion.

PETERS, Edgar (1991), Chaos and Order in the Capital Markets -A New View of Cycles, Prices, and Market Volatility, New York: Wiley.

PETERS, Edgar (19 94), Fractal Market Analysis- Applying Chaos Theory to Investment and Economics, New York: Wiley.

REDER, M. (1982), “Chicago Economics: Permanence and Change”, Journal of Economic Literature, 35, 1-38.

RUELLE, David (1991), Hazard et Chaos, Paris: Odile Jacob.

SARGENT, T. \& WALLACE, N. (1976), "Rational Expectations and the Theory of Economic Policy", Journal of Monetary Economics, 2.

SCHEINKMAN, José \& WOODFORD, Michael (1994), "Self-Organized Criticality and Economic Fluctuations", American Economic Review, 84(2), May, pp. 417 -21.

TURING, Alan (1952), “The Chemical Basis of Morphogenesis”, Philosophical Transactions of the Royal Society of London, 237(B641), pp. 37-72.

WEINTRAUB, R. \& MIROWSKI, P. (1994), “The Pure and the Applied: Bourbakism Comes to Mathematical Economics", Science in Context, 7(2), pp. 245-72.

WITT, Ulrich (ed., 1993), Evolutionary Economics, Aldershot: Edward Elgar.

XIA, Zhihong (1994), "Arnold Diffusion and Oscillatory Solutions in the Planar Three-Body Problem”, Journal of Differential Equations, 110, 289-321. 